\title{
ВОЗРАСТ ГРАНИТОИДОВ И АССОЦИИРУЮЩЕГО МОЛИБДЕН- ПОРФИРОВОГО ОРУДЕНЕНИЯ КОРКОДОНО-НАЯХАНСКОЙ ЗОНЫ, СЕВЕРО-ВОСТОК РОССИИ
}

\author{
В. В. Акинин ${ }^{1}$ Е. Е. Колова ${ }^{1}$ Н. Е. Савва ${ }^{1}$ Н. А. Горячев ${ }^{1}$, В. Т. Маматюсупов \\ В. М. Кузнецов ${ }^{2}$, А. В. Альшевский ${ }^{1}$ Г. О. Ползуненков ${ }^{I}$ \\ ${ }^{I}$ ФГБУН Северо-Восточный комплексный научно-исследовательский институт \\ им. Н. А. Шило ДВО РАН, г. Магадан \\ ${ }^{2}$ ФГБУ «Всероссийский научно-исследовательский геологический институт \\ им. А. П. Карпинского», г. Санкт-Петербург \\ E-mail: akinin@neisri.ru
}

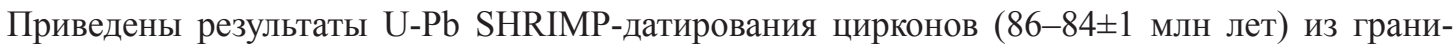
тоидов наяханского комплекса в Коркодоно-Наяханской зоне Охотско-Чукотского вулканоплутонического пояса и $\mathrm{Re}-\mathrm{Os}$ датирования молибденита ( $84.6 \pm 0.5$ млн лет) из молибденпорфировых руд, пространственно совмещенных с малыми телами диоритов. Полученные данные в совокупности с итогами минералогического и термобарогеохимического анализов руд указывают на генетическую связь порфирового оруденения с гранитоидным надсубдукционным магматизмом ОЧВП, залечивающим в позднем мелу унаследованные зоны раскола и растяжения.
\end{abstract}

Ключевые слова: Охотско-Чукотский вулкано-плутонический пояс, гранитоидный магматизм, молибден-порфировые руды, U-Pb датирование цирконов, Re-Os датирование молибденита, генезис месторождений.

DOI: 10.34078/1814-0998-2019-4-3-8

\section{ВВЕДЕНИЕ}

Определение возраста рудно-магматических систем является актуальной задачей металлогении, нацеленной на выработку научно обоснованных методов прогноза и поисков месторождений полезных ископаемых. На Северо-Востоке России главное внимание этому вопросу уделялось в отношении эпитермальных золото-серебряных и орогенных существенно золотых месторождений. Перспективные золотосодержащие медномолибден-порфировые и молибден-порфировые проявления и месторождения в этом отношении практически не исследованы. Настоящая статья посвящена определению возраста гранитоидного магматизма и ассоциирующей с ним молибде-

(C) Акинин В. В., Колова Е. Е., Савва Н. Е., Горячев Н. А., Маматюсупов В. Т., Кузнецов В. М., Альшевский А. В., Ползуненков Г. О., 2019 новой минерализации на месторождении Ак-Су, расположенном в одной из поперечных зон надсубдукционного Охотско-Чукотского вулканоплутонического пояса (ОЧВП).

Известные медно-молибден-порфировые проявления на Северо-Востоке России локализованы в позднемезозойских окраинно-континентальных вулкано-плутонических поясах (Удско-Мургальском, Олойском, Охотско-Чукотском), геодинамическая природа которых традиционно интерпретировалась как надсубдукционная (Парфенов, 1984). Однако последние исследования показывают, что, по крайней мере, для отдельных временных отрезков магматизм, деформации и оруденение в указанных структуpax могут быть проявлены в условиях скольжения литосферных плит (Goryachev, Khanchuk, 2002; Ханчук и др., 2019). В частности, последняя обстановка может быть реконструирована 


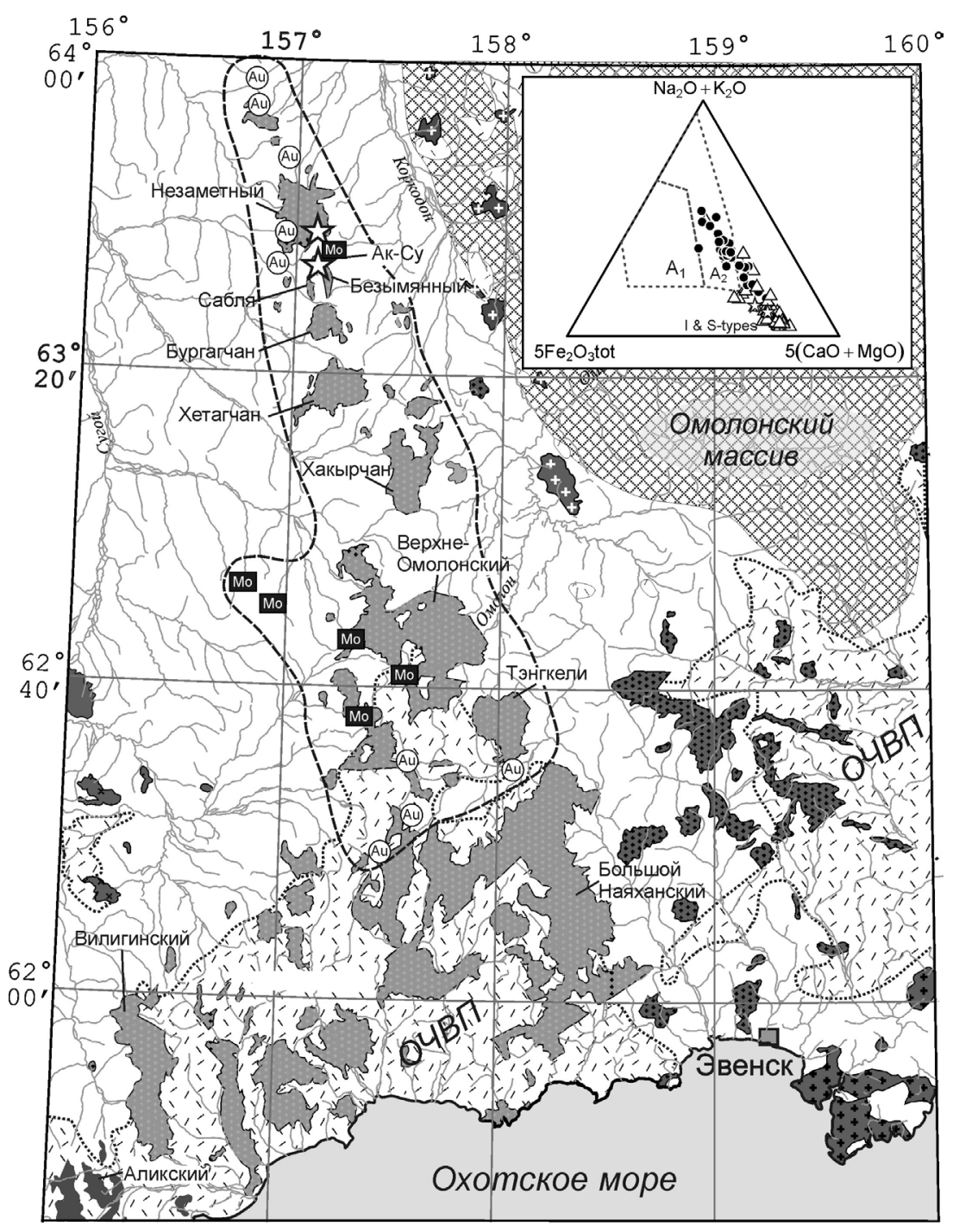

Puc. 1. Схема геологического строения Коркодоно-Наяханской зоны ОЧВП. Одноименная золото-молибденовая металлогеническая зона оконтурена пунктирной линией. Светло-серым показаны позднемеловые гранитоиды, в том числе коньяк-сантонские массивы наяханского комплекca, с которыми связывается оруденение (месторождения и рудопроявления $\mathrm{Au}$ и Мо показаны в квадратах и кружках). Альб-кампанские вулканические породы ОЧВП показаны крапом, палеозойские и архейские комплексы Омолонского массива - сеткой. Звездочки здесь и на врезке - расположение датированных образцов в гранитоидах массива Незаметный и диоритах штока Ак-Су. На врезке - химический состав гранитоидов I-, S- и А -типов наяханского комплекса на диаграмме А. В. Гребенникова (2014), черными кружками показаны гранитоиды из плутонов Большой Наяханский и Вилигинский, треугольниками - остальные массивы

Fig. 1. Structural scheme of the OCVB Korkodon-Nayakhan zone Korkodon-Nayakhan gold-molybdenum metallogenic zone is outlined by the dotted line. Shown in light gray are Late Cretaceous granitoids, including the Cognac-Santon massifs of the Nayakhan complex, with which mineralization is associated (Au and Mo deposits and occurrences are shown in squares and circles). Albian-Campanian volcanic rocks of OCVB are shown in speckles; Paleozoic and Archean complexes of the Omolon massif, with a grid. Asterisks mark the location of dated samples in the granitoids of the Nezametny massif and diorites of the Ak-Su stock. Top right of the inset is the chemical composition of I-, S-, and $\mathrm{A}_{2}$-type granitoids of the Nayakhan complex on the diagram by A. V. Grebennikov (2014); granitoids from Bolshoy Nayakhan and Viligin plutons are shown in black circles; triangles mark the rest massifs для Южно-Анюйской сутурной зоны и Олойского пояса, в которых находится крупнейшее на Дальнем Востоке РФ медно-молибден-порфировое месторождение Песчанка, генетически связанное с монцонитоидами Егдэгкычского плутона раннемелового, берриас-валанжинского возраста (143-139 млн лет, U-Pb метод по циркону, $143.3 \pm 3.0$ и $142.6 \pm 6.9$ млн лет, $\mathrm{Re}-\mathrm{Os}$ метод по молибдениту (Нагорная, 2013; Amato et al., 2015).

\section{ГЕОЛОГИЯ И МИНЕРАЛИЗАЦИЯ}

Перспективные, но слабо исследованные молибденпорфировые проявления известны в Коркодоно-Наяханской металлогенической зоне, которая простирается более чем на 200 км ортогонально к генеральной структуре надсубдукционного ОЧВП и примерно параллельно Омсукчанскому рифтогенному прогибу и западной границе Омолонского кратонного массива (рис. 1). Геологическое строение этой зоны выделяется в виде выразительной цепочки меловых интрузий гранитоидов наяханского комплекса и фрагментов синхронных субаэральных известково-щелочных вулканитов. Гранитоиды прорывают терригенные породы верхоянского комплекса мезозоид и залечивают эту крупную линейную унаследованную зону растяжения. Возраст формирования этих двух поперечных к ОЧВП зон, Омсукчанской и Коркодоно-Наяханской, вероятнее всего также раннемеловой (валанжин-готеривский), судя по возрасту риолитов аскольдинской свиты, выполняющей основание Омсукчанского прогиба (Акинин, Миллер, 2011).

Ранее в крайней северозападной части Коркодоно-Наяханской структуры, между гранитоидными массивами 
Незаметный (Плитук), Безымянный и Сабля государственными поисково-разведочными работами было установлено молибден-порфировое оруденение, сопровождающееся золото-висмутовым и золото-полиметаллическим (см. рис. 1). Молибденовое оруденение проявляется на площади примерно 4 км², образуя штокверковые зоны, имеющие аналогично известным Мо-порфировым рудам Бугдаинского месторождения (Коваленкер и др., 2011) зональнокольцевую морфологию, оконтуривая слабо вскрытые диоритовые штоки, которые, по-видимому, являются частями крупных позднемеловых интрузий наяханского комплекса. Зоны состоят из многочисленных прожилков мощностью от 1-2 до 5-7 см и жил мощностью до 0.8 м, существенно кварцевого состава с вкрапленностью молибденита (содержание Мо варьирует от 0.028 до $0.93 \%$ ), в подчиненном количестве присутствуют арсенопирит, галенит, магнетит, пирит, пирротин, сфалерит, халькопирит, теллуриды Вi и самородное $\mathrm{Au}$ (последние в верховьях руч. Ак-Су). В кварце кварц-молибденитовых жил установлено наличие сингенетичных расплавных и флюидных включений, содержащих твердые фазы галита, магнетита, бликсита, сидерита, альбита и мусковита (Lab Ram HR, ДВГИ ДВО РАH). Определено, что кварц молибденсодержащих руд формировался из гетерофазных (газ, раствор (рассол), расплав), высокотемпературных (от 580 до $300^{\circ} \mathrm{C}$ ) и изначально высококонцентрированных (до 56 мас.\% экв. $\mathrm{NaCl}$ ) флюидов, которые в процессе рудообразования претерпели значительную эволюцию.

Общая площадь выходов гранитоидных плутонов наяханского комплекса составляет около 4428 км $^{2}$ и является одной из наиболее масштабных и выразительных в поперечных структурах в северном Приохотье. В строении массивов комплекса выделяются три интрузивные фазы. В первую (раннюю) фазу объединены небольшие тела и дайки кварцевых диоритов, реже диоритов и диорит-порфиритов. В составе второй главной фазы доминируют гранодиориты, для некоторых массивов характерны кварцевые монцониты. Третью - заключительную фазу составляют граниты, субщелочные граниты и дайки гранитпорфиров. Гранитоидные массивы объединены общей зоной контактово-метаморфических изменений, представленных биотитовыми, биотитмусковитовыми и кордиеритовыми роговиками, кварц-мусковитовыми грейзенами, и сопровождаются обширной геохимической аномалией вольфрама, аномалиями молибдена, висмута и золота.

По химическом составу гранитоиды наяханского комплекса относятся главным образом к магнезиальным, мета- и высокоглиноземистым разностям (ASI от 0.9 до 1.3), умеренно- и высококалиевой известково-щелочной серии. Диориты штока Ак-Су, в котором сконцентрировано перспективное молибденовое оруденение, отличаются пониженными содержаниями редкоземельных элементов и повышенными Cs, $\mathrm{Rb}$. В целом для всех гранитоидов характерны ясно выраженная негативная $\mathrm{Nb}-\mathrm{Ta}$ аномалия, относительно невысокие концентрации $\mathrm{Zr}, \mathrm{Nb}$, и Y. Значение индекса агпаитности больше 0.7 , что позволяет сопоставлять эти породы с гранитоидами вулканических дуг, в частности ОЧВП (Акинин, Миллер, 2011). Изученные нами гранитоиды из северной, наиболее удаленной от ОЧВП части Коркодоно-Наяханской зоны относятся к І-типу (плутоны Незаметный, Безымянный, Сабля и др.), а из южной - пограничной с ОЧВП части зоны (Большой Наяханский и Вилигинский плутоны) по составу могут быть отнесены к А2-типу магматитов в классификации (Гребенников, 2014), формирующихся на этапах локального растяжения континентальных окраин (см. рис. 1, врезка).

\section{РЕЗУЛЬТАТЫ}

Имеющиеся в базе данных «Геохрон» K-Ar датировки гранитоидов Коркодоно-Наяханской зоны укладываются главным образом в интервал от 90 до 75 млн лет, два значения показали более древние, по-видимому, унаследованные даты (Акинин, Котляр, 1997). Для уточнения возраста мы датировали U-Pb SHRIMP-методом цирконы из двух интрузий - Незаметной и АкСу. В акцессорных ассоциациях гранодиоритов массива Незаметный циркон широко развит в виде слабо удлиненных, розоватых, с хорошо выраженной тонкой осцилляционной магматической зональностью кристаллов. Средневзвешенный ${ }^{206} \mathrm{~Pb} / 238 \mathrm{U}$ возраст 11 кристаллов циркона составил $84 \pm 1$ млн лет $($ СКВО $=0.93, \mathrm{p}=$ $0.5)$, табл. 1, рис. 2, a. В диоритах штока Ак-Су среди акцессорных минералов циркона мало, преобладает апатит. Для редких кристаллов циркона наряду с обычными формами $\{111\}$ и $\{110\}$ характерны плохо оформленные, овального габитуса зерна с простой секториальной зональностью. Средневзвешенный ${ }^{206} \mathrm{~Pb} /{ }^{238} \mathrm{U}$ возраст 10 кристаллов циркона штока Ак-Су составил $86 \pm 1.3$ млн лет $(\mathrm{CKBO}=1.4, \mathrm{p}=0.2)$, см. табл. 1 , рис. $2, a$.

$\mathrm{Re}-\mathrm{Os}$ изохронное датирование молибденита из существенно кварцевых руд в штоке Ак-Су показало очень близкий к возрасту кристаллизации диоритов возраст. Для пяти фракций молибденита ТИМС-методом была получена изохрона с возрастом $84.6 \pm 0.5$ млн лет (Initial ${ }^{187} \mathrm{Os} /{ }^{188} \mathrm{Os}=0.48 \pm 0.13$, СКВО = 1.5) - см. рис. 2, б; табл. 2 . 
Таблица 1. Результаты U-Pb SHRIMP-датирования цирконов из гранитоидов наяханского комплекса Table 1. Results of zircon U-Pb SHRIMP dating from granitoides of Nayakhan complex

\begin{tabular}{|c|c|c|c|c|c|c|c|c|c|c|c|}
\hline $\begin{array}{c}\text { Точ- } \\
\text { ка }\end{array}$ & $\begin{array}{c}\% \\
{ }^{206} \mathrm{~Pb}_{\mathrm{c}}\end{array}$ & $\mathrm{U}, \mathrm{ppm}$ & $\begin{array}{l}\text { Th, } \\
\text { ppm }\end{array}$ & ${ }^{232} \mathrm{Th} /$ & $\begin{array}{c}{ }^{206} \mathrm{~Pb}^{*} \\
\mathrm{ppm}\end{array}$ & $\begin{array}{c}(2) \\
{ }^{206} \mathrm{~Pb} /{ }^{238} \mathrm{U} \\
\text { возраст }\end{array}$ & $\stackrel{(1)}{{ }^{207} \mathrm{~Pb} * / 235 \mathrm{U}}$ & $\pm \%$ & ${ }^{206} \mathrm{~Pb} * / 238 \mathrm{U}$ & $\pm \%$ & $\begin{array}{l}\text { err } \\
\text { corr }\end{array}$ \\
\hline \multicolumn{12}{|c|}{$\begin{array}{c}\text { Обр. 10501, гранодиорит массива Незаметный. } \\
\text { Средневзвешенный }{ }^{206} \mathrm{~Pb} / 238 \mathrm{U} \text { возраст } 11 \text { кристаллов }=84 \pm 1 \text { млн лет }(\mathrm{CKBO}=0.93, \mathrm{p}=0.5)\end{array}$} \\
\hline 1 & 1.51 & 250 & 193 & 0.80 & 2.79 & $82.5 \pm 1.6$ & 0.0750 & 16.0 & 0.01279 & 2.1 & 0.131 \\
\hline 2 & 1.61 & 156 & 133 & 0.88 & 1.74 & $80.9 \pm 1.9$ & 0.0980 & 16.0 & 0.01276 & 2.5 & 0.158 \\
\hline 3 & 0.70 & 467 & 307 & 0.68 & 5.28 & $84.1 \pm 1.4$ & 0.0783 & 8.2 & 0.01306 & 1.7 & 0.213 \\
\hline 4 & 1.04 & 254 & 245 & 1.00 & 2.99 & $86.9 \pm 1.7$ & 0.0862 & 11.0 & 0.01354 & 2.0 & 0.180 \\
\hline 5 & 0.47 & 204 & 144 & 0.73 & 2.32 & $84.1 \pm 1.8$ & 0.0912 & 11.0 & 0.01317 & 2.1 & 0.200 \\
\hline 6 & 0.62 & 294 & 303 & 1.07 & 3.36 & $84.6 \pm 1.4$ & 0.0915 & 7.3 & 0.01325 & 1.7 & 0.231 \\
\hline 7 & 0.00 & 187 & 129 & 0.72 & 2.15 & $85.7 \pm 1.6$ & 0.0919 & 5.3 & 0.01341 & 1.8 & 0.345 \\
\hline 8 & 0.68 & 300 & 205 & 0.71 & 3.37 & $83.7 \pm 1.4$ & 0.0780 & 13.0 & 0.01300 & 1.8 & 0.133 \\
\hline 9 & 0.58 & 231 & 160 & 0.71 & 2.62 & $84.4 \pm 1.5$ & 0.0847 & 7.9 & 0.01316 & 1.8 & 0.225 \\
\hline 10 & 1.16 & 110 & 119 & 1.12 & 1.28 & $86.1 \pm 1.9$ & 0.0890 & 14.0 & 0.01345 & 2.2 & 0.155 \\
\hline 11 & 0.56 & 236 & 206 & 0.90 & 2.63 & $83.1 \pm 1.5$ & 0.0777 & 8.5 & 0.01290 & 1.8 & 0.210 \\
\hline \multicolumn{12}{|c|}{$\begin{array}{c}\text { Обр. 10122, диорит штока Ак-Су. } \\
\text { Средневзвешенный }{ }^{206} \mathrm{~Pb} /{ }^{238} \mathrm{U} \text { возраст } 10 \text { кристаллов }=86 \pm 1.3 \text { млн лет }(\mathrm{CKBО}=1.4, \mathrm{p}=0.2)\end{array}$} \\
\hline 1 & 1.13 & 126 & 100 & 0.82 & 1.510 & $88.0 \pm 1.5$ & 0.0920 & 14.0 & 0.01376 & 1.8 & 0.1 \\
\hline 2 & 2.46 & 42 & 61 & 1.50 & 0.514 & $89.1 \pm 2.8$ & 0.0960 & 28.0 & 0.01396 & 3.4 & 0.1 \\
\hline 3 & 0.00 & 102 & 88 & 0.89 & 1.210 & $88.1 \pm 1.5$ & 0.0847 & 8.3 & 0.01370 & 1.7 & 0.2 \\
\hline 4 & 0.00 & 61 & 49 & 0.83 & 0.740 & $90.3 \pm 3.5$ & 0.1010 & 10.0 & 0.01418 & 3.9 & 0.4 \\
\hline 5 & 1.86 & 82 & 95 & 1.19 & 0.959 & $85.6 \pm 1.7$ & 0.0840 & 23.0 & 0.01333 & 2.2 & 0.1 \\
\hline 6 & 2.86 & 50 & 43 & 0.88 & 0.590 & $86.5 \pm 2.2$ & 0.0800 & 37.0 & 0.01343 & 3.0 & 0.1 \\
\hline 7 & 1.95 & 78 & 89 & 1.19 & 0.913 & $86.0 \pm 1.8$ & 0.0880 & 23.0 & 0.01343 & 2.3 & 0.1 \\
\hline 8 & 0.00 & 316 & 671 & 2.20 & 3.610 & $85.3 \pm 0.9$ & 0.0868 & 4.7 & 0.01331 & 1.0 & 0.2 \\
\hline 9 & 2.36 & 46 & 51 & 1.14 & 0.514 & $80.8 \pm 2.2$ & 0.0870 & 26.0 & 0.01265 & 2.9 & 0.1 \\
\hline 10 & 0.00 & 346 & 815 & 2.43 & 3.950 & $85.05 \pm 1.0$ & 0.0876 & 4.7 & 0.01328 & 1.1 & 0.2 \\
\hline
\end{tabular}

Примечание. Погрешность возраста и изотопных отношений - 1 сигма. ${ }^{206} \mathrm{~Pb}_{\text {с }}{ }^{206} \mathrm{~Pb}^{*}-$ доли обыкновенного и радиогенного свинцов, соответственно. (1) - скорректировано на ${ }^{204} \mathrm{~Pb},(2)$ - скорректировано на ${ }^{207} \mathrm{~Pb}$. Погрешность калибровки стандарта Темора - 0.40-0.38\%, err corr - коэффициент корреляции ошибок.
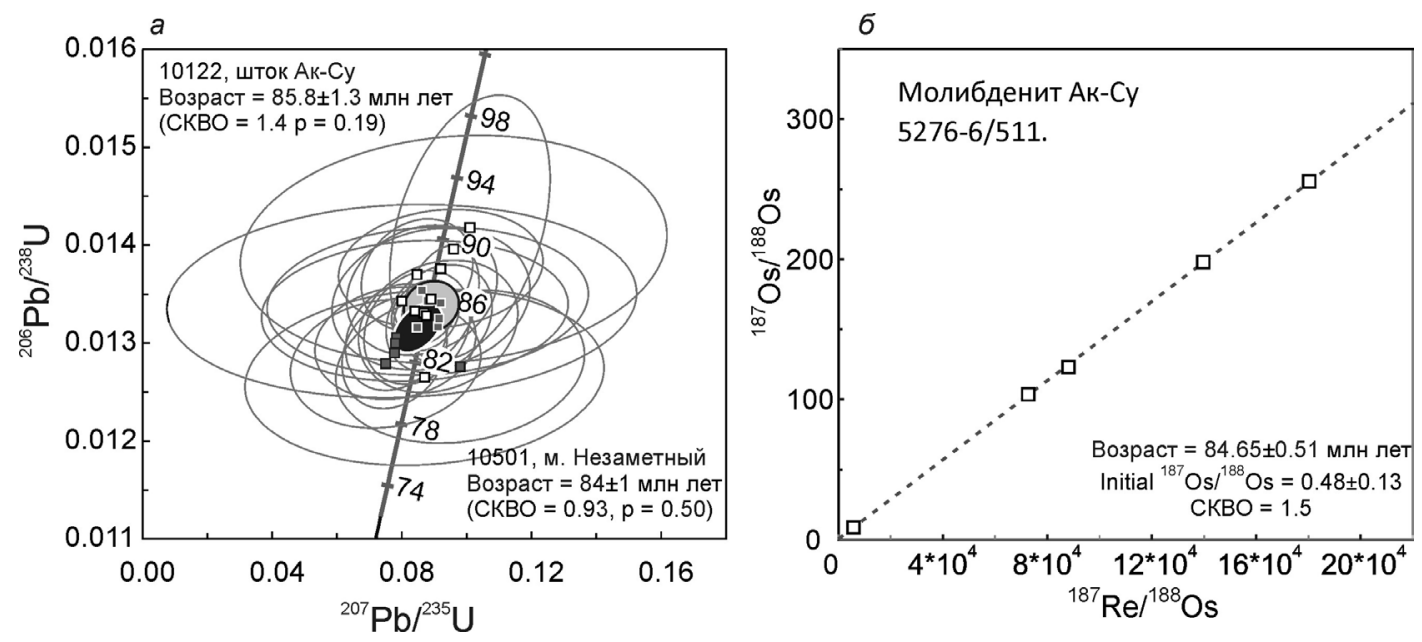

Puc. 2. Результаты U-Pb SHRIMP-датирования цирконов из гранитоидов наяханского комплекса $(a)$ и Re-Os изохрона по молибдениту проявления Ак-Су (б). Датировки выполнены в ЦИИ ВСЕГЕИ (г. Санкт-Петербург)

Fig. 2. Results of U-Pb SHRIMP dating of zircons from granitoids of the Nayakhan complex (a) and the Re-Os isochron for molybdenite from the Ak-Su occurrence (б). Dating performed at VSEGEI ( St. Petersburg) 
Таблица 2. Результаты Re-Os изотопного анализа молибденита проявления Ак-Су

Table 2. Results of Re-Os isotopic analysis of molibdenite from the Ak-Su occurrence

\begin{tabular}{|c|c|c|c|c|c|c|c|c|c|c|c|c|}
\hline № фр. & $\begin{array}{c}\text { Масса, } \\
\text { мг }\end{array}$ & $\begin{array}{c}\mathrm{Re}, \\
\mathrm{ppm}\end{array}$ & $2 \delta, \%$ & $\begin{array}{c}187 \mathrm{Re}, \\
\mathrm{ppb}\end{array}$ & $2 \delta, \%$ & $\begin{array}{c}{ }^{187} \mathrm{Os}, \\
\mathrm{ppb}\end{array}$ & $2 \delta, \%$ & ${ }^{187} \mathrm{Re} /{ }^{188} \mathrm{Os}$ & $2 \delta, \%$ & ${ }^{187} \mathrm{Os} /{ }^{188} \mathrm{Os}$ & $\begin{array}{c}\mathrm{T} \\
\text { err, \% }\end{array}$ & $\begin{array}{c}\mathrm{model}, \\
\mathrm{Ma}\end{array}$ \\
\hline 3652 & 0.77 & 5.45 & 0.8 & 3426 & 0.84 & 5.117 & 0.667 & 5799 & 0.837 & 8.662 & 1.15 & 90 \\
\hline 3668 & 8.78 & 5.14 & 0.4 & 3229 & 0.38 & 4.576 & 0.093 & 139778 & 0.376 & 198.07 & 1.71 & 85 \\
\hline 3669 & 10.74 & 3.17 & 0.4 & 1990 & 0.42 & 2.779 & 0.108 & 88118 & 0.419 & 123.06 & 1.47 & 84 \\
\hline 3671 & 9.54 & 2.49 & 0.4 & 1566 & 0.37 & 2.235 & 0.039 & 72610 & 0.365 & 103.58 & 1.68 & 86 \\
\hline 3672 & 11.45 & 2.78 & 0.3 & 1746 & 0.35 & 2.473 & 0.101 & 180313 & 0.346 & 255.44 & 0.65 & 85 \\
\hline
\end{tabular}

Изохронный возраст $=84.65 \pm 0.51$ млн лет, Initial ${ }^{187} \mathrm{Os} /{ }^{188} \mathrm{Os}=0.48 \pm 0.13$, СКВО $=1.5$

Примечание. № фр. - номер микронавески молибденита; $2 \delta$ - погрешность измерений, Т model - модельный возраст; СКВО - среднеквадратичное отклонение. Анализы выполнены ТИМС-методом в ЦИИ ВСЕГЕИ (г. Санкт-Петербург).

Разброс концентраций Re в микрофракциях молибденита составил от 2.5 до $5.5 \mathrm{ppm}$ (табл. 2).

\section{ВЫВОДЫ}

В Коркодоно-Наяханской зоне ОЧВП диоритгранодиоритовый магматизм наяханского комплекса I- и А-типов и связанная с ним молибденовая минерализация имеют единый позднемеловой сантонский возраст, что в совокупности с геолого-структурными, минералогическими и термобарогеохимическими данными позволяет сделать заключение об их генетической связи в рамках единой рудно-магматической системы, указывает на генетическую связь порфирового оруденения с гранитоидным надсубдукционным магматизмом ОЧВП, залечивающим в позднем мелу далеко проникающие в континент более древние унаследованные зоны раскола и растяжения.

Исследования выполнены при поддержке гранта № 18-2-015 комплексной программы ДВО РАН «Дальний Восток».

Выражаем признательность АО «Дукатская ГГК» за часть предоставленных для исследования образцов.

\section{ЛИТЕРАТУРА}

Акинин В. В., Котляр И. Н. ГЕОХРОН - компьютерная база данных изотопного датирования минералов, горных пород и руд Северо-Востока России // Магматизм и оруденение Северо-Востока России / под ред. С. Г. Бялобжеского. Магадан : СВКНИИ ДВО РАН, 1997. С. 313-318.

Акинин В. В., Миллер Э. Л. Эволюция известковощелочных магм Охотско-Чукотского вулканогенно- го пояса // Петрология. 2011. Т. 19, № 3. С. 249290.

Гребенников А. В. Гранитоиды А-типа: проблемы диагностики, формирования и систематики // Геология и геофизика. 2014. Т. 55, № 9. С. $1356-$ 1373.

Коваленкер В. А., Киселева Г. Д., Крылова Т. Л., Андреева О. В. Минералогия и условия формирования руд золотоносного W-Мо-порфирового Бугдаинского месторождения (Восточное Забайкалье, Россия) // Геология рудных месторождений. 2011. Т. 53, № 2. C. 107-142.

Нагорная $E . \quad B$. Минералогия и зональность молибден-медно-порфирового рудного поля Находка, Чукотка : автореф. дис. ...канд. геол.-минер. наук. М., 2013. $27 \mathrm{c}$.

Парфенов Л. М. Континентальные окраины и островные дуги в мезозоидах северо-востока Азии. Новосибирск : Наука, 1984. 192 с.

Ханчук А. И., Гребенников А. В., Иванов В. В. Альб-сеноманский окраинно-континентальный орогенный пояс и магматическая провинция тихоокеанской Азии // Тихоокеан. геология. 2019. Т. 38, № 3. C. 4-37.

Amato J. M., Toro J., Akinin V. V., Hampton B. A., et al. Tectonic evolution of the Mesozoic South Anyui suture zone, eastern Russia: A critical component of paleogeographic reconstructions of the Arctic region // Geosphere. 2015. Vol. 11, No. 5. P. 1530-1564.

Goryachev N. A., Khanchuk A. I. The Origin of Late Cretaceous alkaline granitoids and basalts in the Upper Kolyma River area (the slab window tectonic model) // Deep-seated magmatism, magmatic sources, and the problem of the plumes: Proceedings of international workshop. Vladivostok : Dalnauka, 2002. P. 261274. 


\title{
AGE OF GRANITOIDS AND THE ASSOCIATED MOLYBDENUM-PORPHYRY MINERALIZATION IN THE KORKODON-NAYAKHAN ZONE, NORTH-EAST OF RUSSIA
}

\author{
V. V. Akinin ${ }^{1}$, E. E. Kolova ${ }^{1}$, N. E. Savva ${ }^{1}$, N. A. Goryachev ${ }^{1}$, V. T. Mamatyusupov', \\ V. M. Kuznetsov' ${ }^{2}$ A. V. Alshevsky ${ }^{I}$, G. O. Polzunenkov ${ }^{I}$ \\ ${ }^{I}$ North-East Interdisciplinary Scientific Research Institute n. a. N. A. Shilo, FEB RAS, Magadan \\ ${ }^{2}$ A. P. Karpinsky Russian Geological Research Institute, St. Petersburg

\begin{abstract}
The paper presents the results of the U-Pb SHRIMP dating of zircons $(86-84 \pm 1 \mathrm{Ma})$ from the Nayakhan complex granitoides of Korkodon-Nayakhan zone of the Okhotsk-Chukotka volcanoplutonic belt (OCVB) and Re-Os dating of molybdenite (84.6 $\pm 0.5 \mathrm{Ma})$ from molybdenum-porphyry ores, spatially associated with the small diorite bodies. The data obtained along with the results of the mineralogical and thermobarogeochemical analyzes of ores indicate genetic relationship of porphyry mineralization and the OCVB supra-subduction granitoid magmatism, curing inherited zone of disruption and extension in Late Cretaceous.
\end{abstract}

Keywords: Okhotsk-Chukotka volcano-plutonic belt, granitoid magmatism, molybdenumporphyry ores, U-Pb zircon dating, Re-Os molybdenite dating, genesis of deposits.

\section{REFERENCES}

Akinin, V. V.; Kotlyar, I. I., 1997, GEOCHRON Computerized Database of Isotopic Dating of Minerals, Rocks, and Ores in the North-East of Russia, Magmatism and Mineralization of Russia's North-East, Magadan, NEISRI FEB RAS, 313-318 [In Russian].

Akinin, V. V.: Miller, E. L., 2011, Evolution of CalcAlkaline Magmas of the Okhotsk-Chukotka Volcanic Belt, Petrology, 19 (3), 237-277, DOI: 10.1134/ S0869591111020020.

Amato, J. M.; Toro J.; Akinin, V. V.; Hampton, B. A., et al., 2015, Tectonic Evolution of the Mesozoic South Anyui Suture Zone, Eastern Russia: A Critical Component of Paleogeographic Reconstructions of the Arctic Region, Geosphere, 11, 5, 1530-1564.

Goryachev, N. A.; Khanchuk, A. I., 2002, The Origin of Late Cretaceous Alkaline Granitoids and Basalts in the Upper Kolyma River Area (the Slab Window Tectonic Model), Deep-Seated Magmatism, Magmatic Sources and the Problem of the Plumes, Proceedings of International Workshop, Vladivostok, Dalnauka, 261-274.
Grebennikov, A. V., 2014, A-Type Granites and Related Rocks: Petrogenesis and Classification, Russian Geology and Geophysics, 55 (9), 1074-1086.

Khanchuk, A. I.; Grebennikov, A. V.; Ivanov, V. V., 2019, Alb-Cenomanian Marginal Continental Orogenic Belt and the Magmatic Province of Pacific Asia, Pacific Geology, 38, 3, 4-37 [In Russian].

Kovalenker, V. A.; Kiseleva, G. D.; Krylova, T. L.; Andreeva, O. V., 2011, Mineralogy and Ore Formation Conditions of the Bugdaya Au-bearing W-Mo Porphyry Deposit, Eastern Transbaikalia, Russia, Geology of Ore Deposits, 53, 2, 93-125.

Nagornaya, Ye. V., 2013, Mineralogy and Zonality of the Nakhodka Molybdenum-Copper-Porphyry Ore Field, Chukotka, Author's Abstr. Diss. ... Cand. Sci. (Geology \& Mineralogy), Moscow [In Russian].

Parfenov, L. M., 1984, Continental Margins and Island Arcs in the Mesozoids of Northeast Asia, Novosibirsk, Nauka [In Russian]. 